\title{
A User Readiness Model of Social Media for Learning among Polytechnic Students in Nigeria
}

\author{
Nura Anka Abubakar ${ }^{1}$, Nazmona Mat Ali ${ }^{1}$, Norasnita Ahmad ${ }^{1}$, Ibrahim Anka Salihu ${ }^{2}$ \\ ${ }^{1}$ Universiti Teknologi Malaysia \\ Sultan Ibrahim Chancellery Building, Johor Bahru, 81310, Malaysia \\ ${ }^{2}$ Abdu Gusau Polytechnic \\ Talata Mafara, Zamfara, Nigeria
}

DOI: $10.22178 /$ pos.47-4

LCC Subject Category: T58.5-58.64

Received 28.05.2019

Accepted 25.06.2019

Published online 30.06.2019

Corresponding Author:

Ibrahim Anka Salihu

isankah3@gmail.com

(c) 2019 The Authors. This article

is licensed under a Creative

Commons Attribution 4.0 License

(c) (i)

\begin{abstract}
The adoption of Internet resources for learning continues to grow in the world today. Despite the abundant benefit of utilizing social media due to the growth of web 2.0, an internet resource for communication and interaction, its use has not been fully embraced as a teaching tool in Nigeria. Social media is becoming a prominent communication tool and found to be facilitating teaching and learning activities among students. However, the user readiness of social media in learning by the students has been challenging. Despite the wide acceptance of social media (such as Facebook, Twitter, and WhatsApp, e.t.c.) amongst Nigerian polytechnic students, they do not utilize it for academic pursuit. This study examined the Use of Social Media among students in Nigerian Polytechnics. The main objective of this study is to find out the user readiness' factors that influence the use of social media by the students in Nigerian Polytechnic. The evaluation results show that social media is an indispensable Internet platform among Nigerian Polytechnic students.
\end{abstract}

Keywords: social media; user readiness; readiness factors.

\section{INTRODUCTION}

The popularity of the internet and the spread of other electronic technologies/devices have transformed businesses and interaction [20]. This has led to the growth of a new phenomenon known as a social network. Social network sites began in 1997 with the launch of SixDegrees.com which "allowed users to create profiles, list their Friends and, beginning in 1998, surf the Friends list". Since that time, SNSs have hit the mainstream with a vengeance. Two websites, in particular, have become very popular: MySpace and Facebook [19]. Social media can be defined as a group of internet web-based applications that form on technological foundations of web 2.0 which allows the creation and exchange of usergenerated. In 2011 types of research on the use of social media, revealed that student in Nigerian institutions used social media platform for chatting, dating, sharing photos and videos, as well it can be used for learning if the students are properly guided [18].
The rapid development and recognition of web 2.0 applications have generated a new world of communication and collaboration among users. Many individuals around the globe are connected. They sustain their selves via wikis, podcast, interactions, comments and instant messaging. Web 2.0 application as enabled by the general transmission of a high-speed network, the internet has emerged as the main medium of communication and interaction which increase significantly in information and society in which we live today. With the enhancement in wireless communication, cloud computing, and mobile computing, the world has turned to a global village. But presently the use of web 2.0 and introduction of social network (e.g. Facebook, Tweeter, WhatsApp, Skype, LinkedIn, Pinterest and Friendster among others) world has taken another pattern in terms of communication, collaboration, opportunity, and interaction. Today distance is not a restriction and the world has become a global round table where people from 
different countries and even continent would communicate easily.

Social media such as Facebook, Twitter, and WhatsApp currently has turned in to extremely popular and grant an easy access and efficient way of sharing information, social media platforms allows individual to share ideas and knowledge which can increase the level of interaction that occurred within the student, this indicates that students have self-regulating in online learning and frequently interact with peers which leads to a higher efficiency and effectiveness [12]. Innovation trigger an individual to be the first users of new technology. They don't believe the new technology as a complex or difficult to understand [11]. They are excited about the presence of new technology and try to use it based on professional knowledge [17]. However, [24] in his study stated that users with a particular specialization that had a high level of innovativeness tend to increase network utilization. Optimism is a positive value of technology and attitude that offer people improved control, flexibility and efficiency in their lives [11, 22, 10]. Discomfort Is the lack of control over technology and desire of being overwhelmed by it $[11,22$, 10]. Insecurity disbelieves of technology from skepticism about its ability to perform properly and concern about its possible destructive consequences [11, 22, 10]. For example, authors [4] on the acceptance of social media as a learning tool at Bahrain University verify student readiness to use social media for learning and that perceived usefulness and perceived ease of use are very vital factors for predicting students' behavior intention toward using social media for learning. In addition, a study on students' readiness towards virtual classroom use for learning in Palestine conducted by [8] emphasized that the students have a positive attitude toward the utilization of e-learning.

Some studies have mentioned and attend to various issues of readiness in using and adopting social media applications for teaching and learning among staffs and students. Such example of the study was conducted by [3] on the awareness and knowledge perceptions of academic staff in utilizing e-learning in Malaysia and it was discovered that e-learning training was practically important in predicting e-learning readiness among the students. As reported by $[6,14]$ some developed and developing countries such as Malaysia, Japan, Saudi Arabia, China, the UK, and the USA use social media in teaching and learning. A simi- lar study was conducted by [1] which he developed an instrument to measure an individual perceived readiness to use social media for learning, and effort was made to statistically measure student readiness to adopt social media for learning since its new technology which is presently receiving the attention of educators all over the world. According to [5] in his study found that social media platforms such as Facebook are used in teaching and learning tool purposely because it possesses some qualities such as providing feedback, social context and communication tools among student.

Despite the abundant benefit of utilizing social media which is an offshoot of web 2.0, an internet resources for interaction and communication, the study revealed that it is not been fully use and adopted as a teaching and learning tool in Nigeria [23]. The study further indicates the readiness of social media for teaching and learning in Nigeria and indicated a strong readiness on the part of the student and therefore, educators are encouraged to use the advantage of this to deploy several social media platforms for content delivery to the student [23].

This becomes very important because of the felt needs to influence teaching and learning through social media and to equip them with adequate skills to make them functional members of the current knowledge culture and lifelong learners. In addition faculty members could generate a devoted account for a course on social media for teaching and learning through uploading learning content such as text, stream-video or make a link to other relevant internet resources that will be of use for student learning [23, 2]. Therefore, in this study, the effort would be made to measure student readiness to adopt social media for gaining knowledge since it is a new platform which is presently contributing the interest of educators all over the world.

\section{METHODOLOGY}

This section describes the methodology used in the research. The methodology adopted is a qualitative method in which a survey is conducted among students. The sample of the study consists of 217 students from Diploma and higher national Diploma from three different polytechnics in the north-west of Nigeria. A total of $46.5 \%$ of the respondents uses Facebook, $22.5 \%$ of the respondents use Twitter and $31 \%$ 
of the respondents use WhatsApp. The data was analyzed using Smart PLS 2.0 as the study involved various learning styles. The demographic details were analyzed using descriptive statistics based on the Statistical Program for Social Sciences (SPSS). This was accomplished using descriptive statistics such as frequency and percentages.

\section{Research Model}

This section presents the Technology Readiness and Acceptance Model (TRAM) proposed in this research. The previous study shows that many researchers integrate the construct of technology readiness model with the technology acceptance model into one model and proposed technology readiness and acceptance model (TRAM) [15]. The TRAM has been selected for the study in order to investigate user readiness factors. Tech- nology readiness has a great influence on student willingness to accept the new technology for learning.

The adopted model as shown in Figure 1 was derived from various literature of TRAM model applied in the various study. However, in order to enhance and improve the adopted model other two factors were adapted namely student's satisfaction and collaboration. For instance authors in [10] offered innovativeness and optimism as the positive technology readiness factors and insecurity and discomfort as the negative factors in order to find the Facebook users' intention to use Facebook and discovered that positive technology readiness had a positive impact and negative technology readiness had a negative impact on individual perceived usefulness and perceived ease of use when using social media.

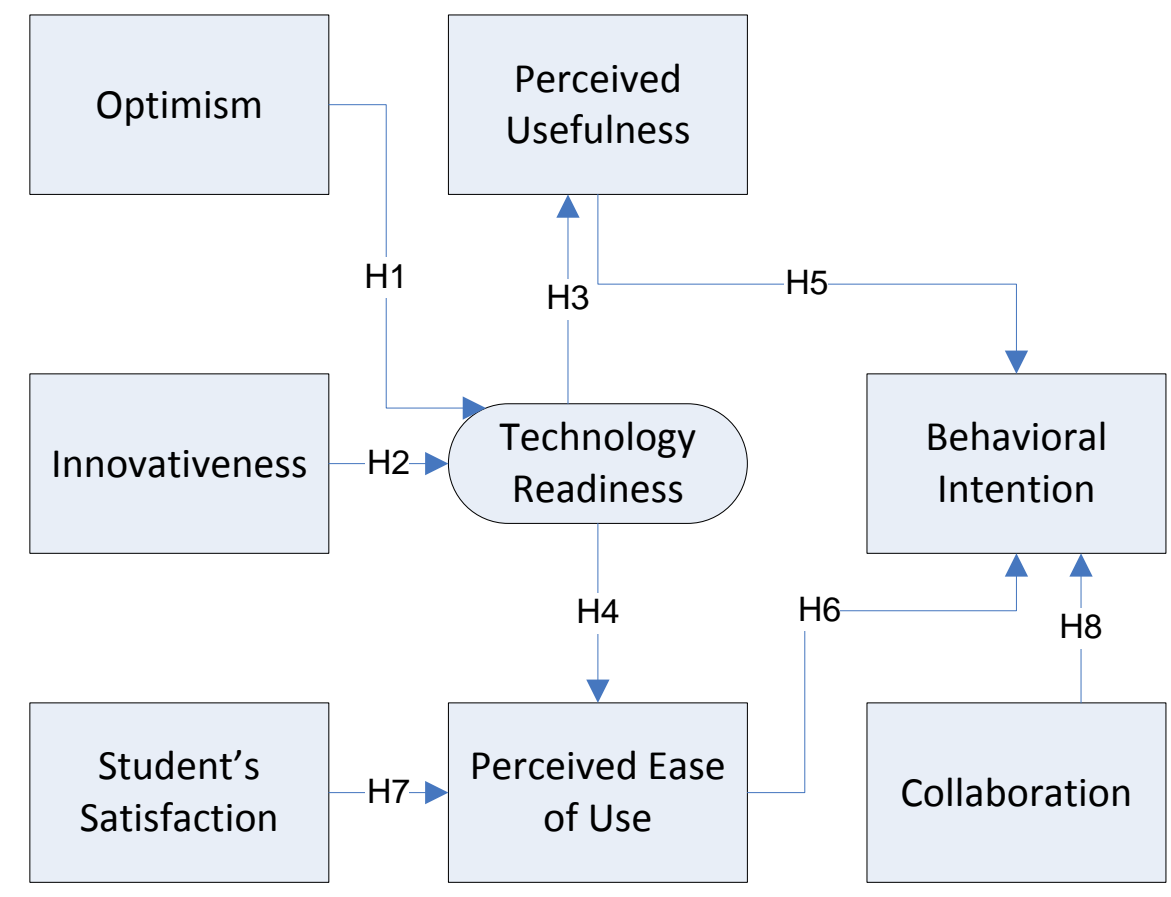

Figure 1 - Research Model

On the basis of the above argument the first and second hypotheses are developed as follows:

H1: Optimism has a significant influence on technology readiness.

H2: Innovativeness has a significant influence on technology readiness. Technology readiness is mostly known as a critical factor for influencing user acceptance and usage of new technology
[13]. This study proposes the following hypothesis.

H3: Technology Readiness has a significant influence on perceived usefulness

H4: Technology readiness significant influence on perceived ease of use. According to the Tam perceived ease of use is a determinant of perceived usefulness [25]. When users perceived ease while using the technology they are more 
possible to believes the technology to be helpful and useful for a specific purpose. For that, the following hypotheses were recognized.

H5: Perceived usefulness has a significant influence on behavioral intention to use social media.

H6: Perceived ease of use will influence on behavioral intention to use social media. Satisfaction and Collaboration in online learning are due to Perceived ease of use and perceived usefulness [9]. A platform such as Facebook is used to develop a conversational forum and enhance the learning process [7]. According to this argument the seventh and eight hypotheses are developed as follows:
H7: Student satisfaction has a significant influence on perceived Ease of use

H8: collaboration significant influence on behavioral intention to use social media.

Bootstrapping (217 resample) was performed to obtain the statistical significance of path coefficients using a t-test. All the results were considered significant at a p-value of $<0.05$. In path modeling, indicators with loadings greater than 0.7 are generally retained, and those ranging from 0.40 to 0.70 are excluded only if their exclusion increases the composite reliability (CR) [21]. As the results indicate in Figure 2, the majority of the indicator loadings were greater than 0.7.

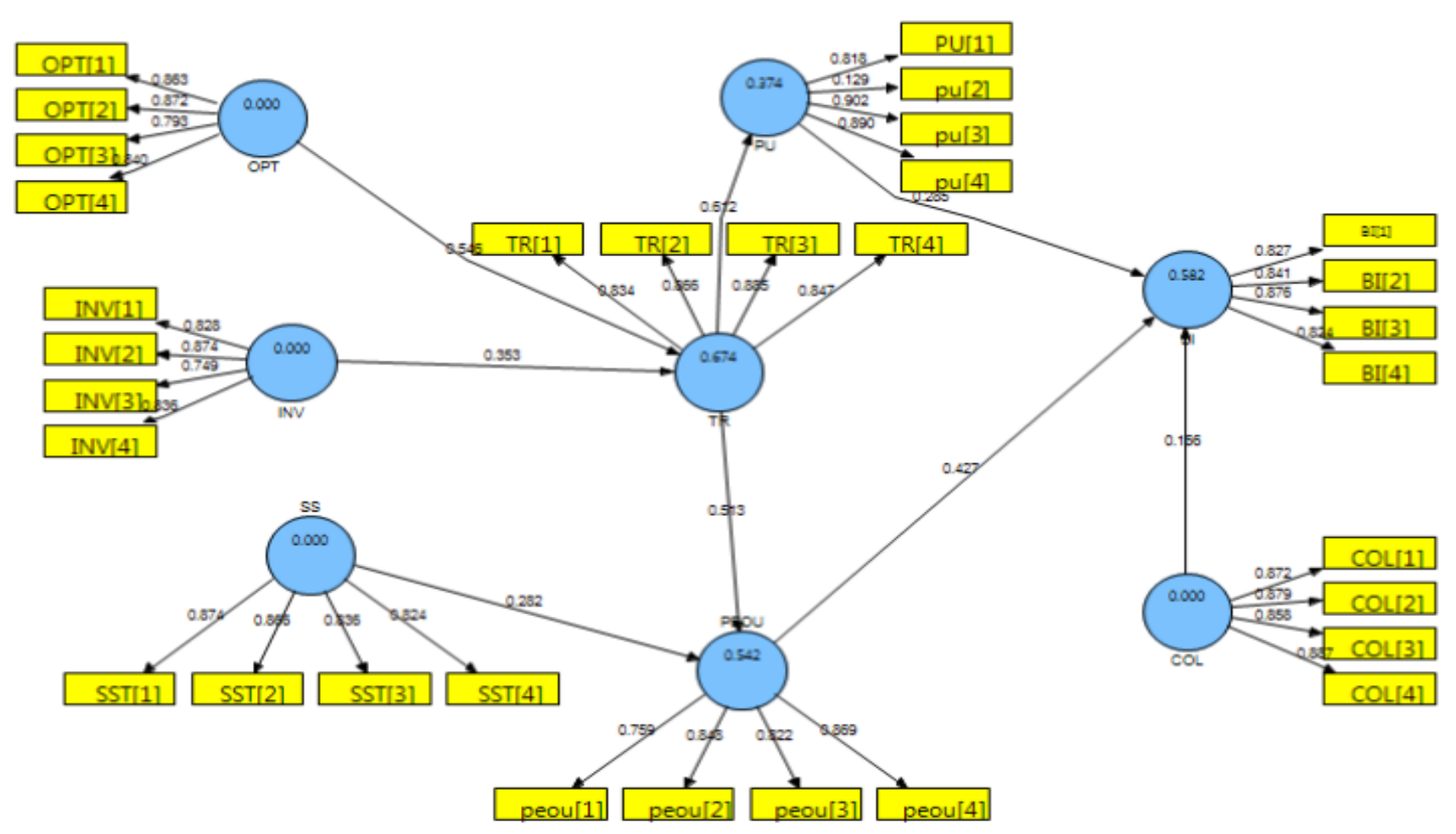

Figure 2 - Model of the analysis

These items were retained as their exclusion had no effect on the overall CR. As all of the constructs TRAM were based on reflective multiitem scales, they were also assessed in terms of their reliability and validity. This was ensured with the following criteria: (1) CR greater than $0.7,(2)$ average variance extracted (AVE) values greater than 0.5 , (3) Cronbach's alpha (CA) values above 0.7, and (4) the Fornell-Larcker criterion (each construct should be higher than the construct's highest squared correlation with any other latent construct) [21].

\section{RESULTS AND DISCUSSION}

The hypothesis correlation test results show that the correlation test outcomes were significance base on the $P$ value at 0.05 levels. The outcome of bootstrapping shows that the significant structural relationship in the model and path coefficients revealed that all path coefficients were supported except student's satisfaction and collaboration.

In order to achieve the research objective, user readiness factors were identified and study. Data and information related to user readiness of social media for learning were collected from re- 
lated literature namely, books, internet, and journals. The research model was tested using Smart PLS the results indicate that the research model provides an effective prediction on user readiness of social media for learning. The hypotheses testing results shows that all the hypothesis are supported except Student's satisfaction and collaboration. The findings contributed by recognizing the benefit of user readiness model of social media for learning among students.

\section{CONCLUSION}

The analysis revealed that there is frequent use of social media by students. Facebook, WhatsApp, and Twitter are the widest type of social media platform preferred among the students. However, the study shed light on the state of readiness of college students to social media use for learning in Nigeria. Therefore, educators had been prompted to take advantages of this to deploy several social media for content material delivery to the students. There are some opportunities for further research that can examine the effect of other potential user readiness.

\section{REFERENCES}

1. Agboola, A. K. (2006). Assessing the awareness and perceptions of academic staff in using e-learning tools for instructional delivery in a post-secondary institution: A case study. The Innovation Journal: The Public Sector. Innovation Journal, 11(3), 1-12.

2. Ahenkorah-Marfo, M., \& Akussah, H. (2016). Being where the users are. Library Review, 65(8/9), 549-563. doi: 10.1108/lr-02-2016-0020

3. Ahmed, A., Khan, A. R., \& Ahmed, S. (2014). Collaboration of Knowledge Network and E-Learning System with Social Sites for Teaching-Learning. 2014 Fourth International Conference on Advances in Computing and Communications. doi: 10.1109/icacc.2014.41

4. Al-Ammary, J. H., Al-Sherooqi, A. K., \& Al-Sherooqi, H. K. (2014). The Acceptance of Social Networking as a Learning Tools at University of Bahrain. International Journal of Information and Education Technology, 4(2), 208-214. doi: 10.7763/ijiet.2014.v4.400

5. Al-rahimi, W. M., Othman, M. S., \& Musa, M. A. (2013). Using TAM Model To Measure The Use Of Social Media For Collaborative Learning. International Journal of Engineering Trends and Technology, 5(2), 90-95.

6. Farhan, A. B. (2014). Students Awareness of using Facebook in terms of readiness in Hail University. International Journal of Advanced Research, 2(7), 1216-1221.

7. Guo, R., Shen, Y., \& Li, L. (2018). Using Social Media to Improve Student-Instructor Communication in an Onlinef Learning Environment. International Journal of Information and Communication Technology Education, 14(1), 33-43. doi: 10.4018/ijicte.2018010103

8. Ilgaz, H., Gülbahar, Y. (2015). A snapshot of online learners: e-Readiness, e-Satisfaction and expectations. International Review of Research in Open and Distributed Learning, 16(2), 171-187.

9. Iqbal, S., \& Bhatti, Z., A. (2015). An Investigation of University Student Readiness towards M-learning using Technology Acceptance Model. International Review of Research in Open and Distributed Learning, 16(4), 83-103.

10. Jin, C. (2013). The perspective of a revised TRAM on social capital building: The case of Facebook usage. Information \& Management, 50(4), 162-168. doi: 10.1016/j.im.2013.03.002

11. Kim, T., \& Chiu, W. (2019). Consumer acceptance of sports wearable technology: the role of technology readiness. International Journal of Sports Marketing and Sponsorship, 20(1), 109-126. doi: 10.1108/ijsms-06-2017-0050

12. Liao, Y.-W., Huang, Y.-M., Chen, H.-C., \& Huang, S.-H. (2015). Exploring the antecedents of collaborative learning performance over social networking sites in a ubiquitous learning context. Computers in Human Behavior, 43, 313-323. doi: 10.1016/j.chb.2014.10.028 
13. Liljander, V., Gillberg, F., Gummerus, J., \& van Riel, A. (2006). Technology readiness and the evaluation and adoption of self-service technologies. Journal of Retailing and Consumer Services, 13(3), 177-191. doi: 10.1016/j.jretconser.2005.08.004

14. Lu, J., \& Churchill, D. (2012). The effect of social interaction on learning engagement in a social networking environment. Interactive Learning Environments, 22(4), 401-417. doi: 10.1080/10494820.2012.680966

15. Lunney, A., Cunningham, N. R., \& Eastin, M. S. (2016). Wearable fitness technology: A structural investigation into acceptance and perceived fitness outcomes. Computers in Human Behavior, 65, 114-120. doi: 10.1016/j.chb.2016.08.007

16. Morofushi, M., Pasfield-Neofitou, S. E. (2014). Normalizing social networking in a beginners' Japanese course. The Language Learning Journal, 42(1), 67-84. doi: 10.1080/09571736.2012.678012

17. Mukerjee, H. S., Deshmukh, G. K., \& Prasad, U. D. (2018). Technology Readiness and Likelihood to Use Self-Checkout Services Using Smartphone in Retail Grocery Stores: Empirical Evidences from Hyderabad, India. Business Perspectives and Research, 7(1), 1-15. doi: $10.1177 / 2278533718800118$

18. Omowal, A., \& Kayode, O. J. (2014). Adapting Social Media for Formal Learning in Nigeria : Challenges and ProspectsSanusi , Bernice Oluwalanu. Oman Chapter of Arabian Journal of Business and Management Review, 3(9), 22-30. doi: 10.12816/0016493

19. Roblyer, M. D., McDaniel, M., Webb, M., Herman, J., \& Witty, J. V. (2010). Findings on Facebook in higher education: A comparison of college faculty and student uses and perceptions of social networking sites. The Internet and Higher Education, 13(3), 134-140. doi: 10.1016/j.iheduc.2010.03.002

20. Salihu, I. A., \& Selamat, A. (2016). Improved Service Responsibility Table of Users' Requirements for EService Systems. Retrieved from https://www.researchgate.net/publication/316823442_Improved_Service_Responsibility_Tabl e_of_Users'_Requirements_for_E-Service_Systems

21. Sánchez, R. A., Cortijo, V., \& Javed, U. (2014). Students' perceptions of Facebook for academic purposes. Computers \& Education, 70, 138-149. doi: 10.1016/j.compedu.2013.08.012

22. Stock, R., \& Gross, M. (2016). How Does Knowledge Workers' Social Technology Readiness Affect Their Innovative Work Behavior? Retrieved from https://ieeexplore.ieee.org/document/7427454

23. Tajudeen, S. A., Isiaka, G. A., Olaler, Y. M., \& Thomas, A. O. (2015). Confirmatory Factor Analysis of the dimensionality of Students' Readiness of using Social-Media for Learning in Nigeria. Journal of Science, Technology \& Education, 3(2), 109-121.

24. Upreti, M., \& Kumar, V. (2017). Learning the student's sufferings using Social Networks. Retrieved from https://ieeexplore.ieee.org/document/8229824

25. Venkatesh, V., Morris, M., Davis, G. \& Davis, F. (2003). User Acceptance of Information Technology: Toward a Unified View. MIS Quarterly, 27(3), 425. doi: 10.2307/30036540 